\title{
Limites dos modelos republicano e liberal relacionados ao estudo da sociedade, economia e direito ${ }^{1}$
}

Camila Concilio Candossim ${ }^{2}$

\begin{abstract}
Resumo
0 trabalho busca expor parte das reflexões elucidadas no projeto de pesquisa "Estado e Relações Empresariais: diálogos filosóficos e jurídicos acerca da regulação estatal sobre a ordem econômica nacional", que, em sua etapa inicial abordou aspectos filosóficos acerca do direito e do Estado. Assim, busca-se demonstrar dois modelos que figuram em pólos contrários: o republicanismo e o liberalismo, abordando seus limites em relação à sociedade, ao direito e à economia. Então, aponta-se, como conclusão, a necessidade de relacionar ambos os modelos em vista da realidade social e da função do Estado. Com a introdução do pensamento fruto da Teoria Social, foi possível perceber a necessidade de relacionar ambas as teorias, uma vez que cada uma possui limites que devem ser observados. Dessa forma, pretende-se analisar determinados aspectos de forma complementar, o que desencadeou a busca pelo pensamento de Jürgen Habermas, o qual busca conciliar a esfera privada à esfera pública dos sujeitos, uma vez que é possível observar a existência de ambas e de acordo com a necessidade de relacioná-las.
\end{abstract}

Palavras-Chave: Republicanismo; Liberalismo; Economia; Direito.

\section{Introdução}

0 presente trabalho, como resultado das reflexões e das discussões acerca do projeto de pesquisa “Estado e Relações Empresariais: Diálogos Filosóficos e Jurídicos acerca da Regulação Estatal sobre a Ordem Econômica Nacional", busca expor algumas das preocupações dos membros do projeto, as quais emergiram a partir de uma série de estudos acerca da origem do Estado, que constitui as primeiras etapas do projeto.

É preciso deixar claro, no entanto, que o objetivo deste texto não é esgotar as discussões realizadas, uma vez que deixará muitos pontos de lado, ao mesmo tempo em que repousará o foco sobre as questões mais problematizadas no decurso do projeto. Mesmo assim, a análise se dará de forma superficial, pois o objetivo é elucidar os pontos mais

\footnotetext{
${ }^{1}$ Artigo desenvolvido sob a orientação do Professor Elve Miguel Cenci, vinculado ao projeto de pesquisa "Estado e Relações Empresariais: diálogos jurídicos e filosóficos acerca da regulação estatal sob a ordem econômica nacional" e ao programa de iniciação científica da Universidade Estadual de Londrina (PROIC/UEL).

${ }^{2}$ Graduanda do quinto ano do curso de Direito da Universisdade Estadual de Londrina.
} 
levantados, e por isso, o trabalho se encontra num campo restrito, pois as teorias não serão amplamente aprofundadas.

$\mathrm{Na}$ verdade, estas questões giram em torno de uma questão maior, relacionada à Ordem Econômica e à possibilidade de intervenção do Estado. Mesmo quando abordadas as raízes filosóficas dos clássicos, tal questão central sempre fora elucidada num contexto de polarização, a partir da defesa do modelo mais adequado para pensar a sociedade.

De forma geral, as reuniões refletiam uma defesa ao liberalismo, diante da crítica à sobrecarga ética de um modelo comunitarista. No decorrer do projeto, no entanto, a reflexão apontava a um caminho que não resultava num fatalismo. Apesar das teorias serem opostas entre si, ambas são necessárias à compreensão da sociedade, seja do ponto de vista da sua realidade como de sua função. Não se trata da defesa de uma absolutamente, do que decorre a desconsideração completa da outra, mas de entender a realidade social e perceber as formas de participação dos indivíduos nela inseridos.

Pensando nisso, o trabalho é dividido em duas partes. Na primeira parte serão expostos os limites de determinados pontos do liberalismo de John Locke através da crítica de Karl M arx, e, na segunda parte, serão expostos argumentos republicanos de Jean Jacques Rousseau, principalmente no que se refere à autonomia política dos cidadãos, seguidos de conseqüente avaliação de Jürgen Habermas.

A importância desta análise, no âmbito do Direito, faz-se imprescindível uma vez que o próprio direito acaba por tomar uma posição liberal diante da realidade, e é preciso entender quais são as conseqüências desta visão. 0 Direito, na verdade, nasceu pensando a sociedade a partir de seu todo, o que leva Bobbio (1992, p. 57) a afirmar que era considerado apenas um aspecto da moral. Como exemplo, 0 autor se utiliza das primeiras regras coordenadas a partir dos Dez Mandamentos, Lei das doze tábuas e o Código de Hamurabi. Todas elas têm em comum imposições, mandamentos e obrigações, ou seja, sua "figura deôntica originária é o dever, não o direito" (BOBBIO, 1992, p. 56).

Para Bobbio (1992, p. 58) a reviravolta do ponto de vista nasce a partir da concepção cristã de fraternidade, mas se desenvolve como doutrina filosófica através do jusnaturalismo "que fez do indivíduo, e não mais da sociedade, o ponto de partida para a construção de uma doutrina da moral e do direito [...]". Esta escola do direito natural elabora a doutrina dos direitos dos homens que está contida nas Declarações dos Direitos 
proclamadas nos Estados Unidos da América, em 1776, e na França Revolucionária em 1789, onde é posto o princípio fundamental do Estado Liberal como Estado limitado: "O objetivo de toda associação política é a conservação dos direitos naturais e não prescritíveis do homem" (artigo $2^{\circ}$ da Declaração dos Direitos do Homem e do Cidadão, 1789).

\section{Limites do liberalismo}

As raízes do liberalismo: John Locke

o que implica afirmar, diante da contextualização histórica, que o direito se desenvolve fundamentado a partir da doutrina do liberalismo? Esta questão remete às bases desta teoria que, como abordado de forma introdutória, surge a partir da concepção jusnaturalista. De acordo com o ponto de vista liberal, a existência do indivíduo possui um valor supremo diante da sociedade, uma vez que esta é composta pela soma dos direitos de cada um. Ou seja, o indivíduo singular existe a priori, com seus interesses e suas necessidades, e a sociedade se configura como um elemento que liga a doutrina dos direitos do homem e o contratualismo (BOBBIO, 1992).

Tal teoria identifica a origem do Estado com o momento de um pacto social em que os indivíduos concordam em abdicar de sua liberdade irrestrita em favor de uma ordem civil a qual deve garantir a conservação do indivíduo e da propriedade, o que resultou em uma subversão da relação entre o indivíduo e a sociedade. Aos olhos de John Locke, pensador do século XVII, o momento do pacto não se configurava como uma ficção, mas um fato histórico. Através do pacto social, o homem cria a sociedade política, delegando poderes a uma terceira pessoa que, imbuída da coação legítima, garante a segurança dos homens e de sua propriedade.

Se todos os homens são, como se tem dito, livres, iguais e independentes por natureza, ninguém pode ser retirado deste estado e se sujeitar ao poder político de outro sem seu próprio consentimento. A única maneira pela qual alguém se despoja de sua liberdade natural e se coloca dentro das limitações da sociedade civil é através de acordo com outros homens para se associarem e se unirem em uma comunidade para uma vida confortável, segura e pacífica uns com os outros, desfrutando com segurança de suas propriedades e melhor protegidos contra aqueles que não são daquela comunidade. (LOCKE, 2001, p. 139) 
A herança jusnaturalista, portanto, se manifesta a partir do momento em que a integridade do indivíduo e da propriedade de seus bens são incorporados ao rol de direitos naturais, considerados inerentes à essência do indivíduo. Para Locke, se tais elementos são princípios do direito natural, são eles que devem estar na base da sociedade organizada politicamente.

0 pacto é uma linha demarcatória entre dois momentos: 0 estado de natureza e 0 estado civil. Para Locke, a natureza do homem é caracterizada pela solidariedade, ele é naturalmente bom e feliz, é livre e respeita as próprias leis. No entanto, este homem isolado e soberano, quando encontra o outro, não o reconhece como igual, deixando de lado o senso de justiça. Dessa forma, é instaurado um estado no qual o gozo da propriedade que possui é incerto e arriscado, pois neste momento são elucidadas questões como: "O que é meu?", "O que é seu?" e "Quem decide?". Ou seja, não havia ao que se reportar, uma vez que o direito que prevalecia era o direito de justiça com as próprias mãos, que arriscava constantemente a conservação da propriedade e inclusive a integridade dos indivíduos.

A partir deste momento, a doutrina liberal dissemina a idéia de que cada indivíduo (dotado da razão e, portanto, igual) deve ter a propriedade legitimada a partir da força de trabalho agregada no objeto.

Ao remover este objeto do Estado comum em que a natureza o colocou, através de seu trabalho adiciona-lhe algo que excluiu o direito comum dos homens. Sendo este trabalho uma propriedade inquestionável do trabalhador, nenhum homem, exceto ele, pode ter direito ao que o trabalho Ihe acrescentou, pelo menos quando 0 que resta é suficiente aos outros, em quantidade e qualidade. (LOCKE, 2001, p. 98)

Pensemos no exemplo da maçã: o homem vai até a macieira, emprega sua força de trabalho para apropriar-se de um objeto, no caso, a maçã e, por isso, é legítima a sua propriedade sobre ela. Resumidamente, e beirando o senso comum, o que um indivíduo tem é fruto do esforço que empregou para obter. Para o liberalismo esta lógica não é óbvia, é natural, e o que é inerente ao indivíduo deve ser garantido e protegido.

Ainda que a terra e todas as criaturas inferiores pertençam em comum a todos os homens, cada um guarda a propriedade de sua própria pessoa: sobre esta ninguém tem qualquer direito, exceto ela. Podemos dizer que o trabalho de seu corpo e a obra produzida por suas mãos são propriedade sua. Sempre que ele tira um objeto do estado em que a natureza o colocou e deixou, mistura nisso o seu trabalho e a 
isso acrescenta algo que the pertence, por isso o tornando sua propriedade. (LOCKE, 2001, p. 98)

O liberalismo utiliza-se dos ensinamentos da ciência econômica buscando enunciar, através das leis naturais da economia, de que forma toda a humanidade pode evoluir economicamente. Neste caso, o Estado não é chamado a interferir, uma vez que ele é limitado, o que é condizente com sua própria finalidade, o "crescimento do indivíduo, tanto quanto possível livre de condicionamentos externos" (BOBBIO, 2000, p. 60).

Enquanto o liberalismo concentra-se em limitar o poder do Estado, a democracia preocupa-se em distribuí-lo, e essa situação gera tensões por parte da doutrina. Norberto Bobbio (2000), em sua obra "Liberalismo e Democracia", afirma que não é uma relação necessária a existente entre o liberalismo e a democracia, muitas vezes, o que se verifica é 0 contrário desta situação, pois um Estado Liberal se realiza plenamente quando observa-se a restrição da participação popular no governo, em que a produção de decisões cabe a uma classe mais possuidora. E é necessário analisar tal contradição uma vez que ambas as noções são pressupostos fundamentais dos Estados contemporâneos em países desenvolvidos em âmbito econômico e social.

A doutrina liberal, então, busca cada vez mais limitar o poder do Estado perante direitos dos indivíduos, o que revela - somado à liberdade e à propriedade privada - uma das características do liberalismo: o individualismo. Segundo Bobbio (2000), não há liberalismo sem individualismo. Além destes preceitos o liberalismo afirma 0 igualitarismo, quando admite e garante a igualdade do homem enquanto pessoa, bem como o universalismo (homogeneidade moral) e o otimismo relacionado ao aperfeiçoamento das instituições sociais.

É preciso deixar claro que não há pretensão alguma de esgotar a análise da doutrina, uma vez que há uma diversidade muito grande entre escolas e interpretações, 0 que dá a entender que tal doutrina é, de certa forma, desarticulada. Isso ocorre pois o liberalismo é uma doutrina que lida com as conseqüências futuras da ação do homem e, por não ser dogmática, sofre várias mudanças através do tempo decorrentes do desenvolvimento científico, o que faz com que ela seja proferida de várias formas. 
Com a palavra, Karl M arx

Em outro extremo, encontramos Karl MarX, teórico que viveu, no século XIX, as transformações na sociedade decorrentes das inovações das técnicas de produção, ou seja, a Revolução Industrial. Diante do rápido crescimento da pobreza da classe operária e proporcional aumento da riqueza da burguesia, Marx buscou compilar uma teoria científica que alcançasse os limites e problemas do operariado e, simultaneamente, que servisse como um instrumento de transformação social.

A complexidade de sua teoria repousa na definição das categorias as quais estruturam seu pensamento e seus escritos revelam uma constante preocupação em analisar e descrever corretamente a sociedade capitalista. No entanto, talvez pela sua forma simples e muitas vezes irônica de descrição dos fatos, os economistas resistem em aceitá-lo como tal, o que levou Oscar Lange (1972, p. 68) a afirmar que esta falta de compreensão não se refere ao âmbito da ciência, mas pessoal, uma vez que tais profissionais são produto de uma classe média com a qual firmaram, tradicionalmente, compromissos sociais.

Para Marx (1972, p. 23), diferentemente de Locke, o homem não pode ser concebido como um ser naturalmente isolado, pelo contrário, ele não é apenas social, "mas um animal que só se transforma em indivíduo dentro da sociedade", ou seja, o homem só pode reconhecer o outro quando o encontra. E esta visão tende a desviar o foco do indivíduo para concentrá-lo nas classes sociais, o que influencia diretamente na noção da origem do Estado. Dessa forma, não é o Estado que cria a sociedade civil, mas é criado por ela (GORENDER, 2000, p. 55). Neste contexto, a sociedade civil se constitui como um "conjunto das relações materiais de vida, cuja anatomia seria estudada pela economia política" (GORENDER, 2000, p. 55).

A formação das classes sociais e a luta de classes criaram a necessidade de um órgão que preservasse a ordem social. Assim, o Estado surge para defender e preservar os interesses dominantes ao mesmo tempo que figura, aparentemente, como elemento separado e acima da sociedade civil, o que o torna apto como árbitro. De acordo com a visão revisada de Friederich Engels, o Estado surge "da cisão da comunidade primitiva em classes antagônicas, processo que acompanhou o crescimento das forças produtivas e a substituição da propriedade comunitária pela propriedade privada" (GORENDER, 2000, p. 55). 
O Estado, necessariamente, abriga as classes sociais, ou seja, o modelo estatal tem um conteúdo de classe, que se caracteriza por ser ditadura, que significa uma condição de dominação que não reconhece restrições. Importa, neste momento, fazer uma diferenciação no conceito de ditadura. A ditadura de Estado não se confunde com a ditadura como forma de governo. Esta se refere ao arbítrio ilimitado enquanto aquela à dominação de uma classe sobre as outras.

Na condição de árbitro, o Estado deve decidir entre o interesse do explorado e do explorador, "mas não pode por em causa a ordem social vigente. 0 limite da sua independência reside nessa ordem social, no caso a ordem social capitalista" (GORENDER, 2000 , p. 57). 0 modelo socialista, ao pressupor uma sociedade sem classes, visa, então, a extinção do poder estatal. Isso porque, a "máquina do Estado burguês" não é compatível ao Estado operário.

Em particular, o proletariado se desfaria da burocracia e do exército permanente. Com 0 advento do proletariado à condição de classe dominante, o Estado deixaria de pairar acima da sociedade, ainda que na aparência. Submetido à sociedade proletarizada, as forças que o Estado extraiu da sociedade, seriam devolvidas a esta, com o que se iniciaria o processo de extinção do próprio poder estatal. (GORENDER, 2000, p. 57)

Neste momento, é possível perceber um ponto de convergência entre 0 pensamento de Locke e Marx, uma vez que ambos associam a criação do Estado com a conservação da propriedade privada. Mas, se Locke trata a propriedade de uma forma ampla, M arx a considera condição da produção, e, mais além, a propriedade privada como uma forma definida de propriedade o que implica a existência de uma forma oposta, ou melhor, a ausência de propriedade. Relacionando com Jean Jacques Rousseau, é possível compreender tal colocação de Marx. Em seu discurso sobre a desigualdade, Rousseau afirma que a propriedade intensifica a desigualdade, pois gera uma oposição fundamentada na riqueza entre aqueles que a possuem e aqueles que não possuem (ROUSSEAU, 1999). A defesa da propriedade privada encontra-se na raiz do pensamento liberal, que a reconhece como fruto do esforço empenhado pelos indivíduos para alcançá-la. Assim, segundo os economistas, a produção é determinada por leis naturais e a distribuição (proporção que os indivíduos recebem) é dependente da oportunidade social. 
Porém, partindo de fatos históricos Marx demonstra que a produção é determinada pela distribuição, por exemplo, "o conquistador, ao distribuir a terra entre seu povo, estabelece, destarte, certa divisão e formas da propriedade das glebas, e determina o caráter da produção" (MARX, 1972, p. 34).

Em todas as conquistas, o método de produção dos conquistadores, dos conquistados, ou resultante da combinação de ambos, determina a natureza da nova distribuição. Embora esta última pareça agora condição prévia do novo período de produção, é em si mesma um produto da produção [...] que se relaciona com um período histórico definido. (M ARX, 1972, p. 36)

Dessa forma, ele critica o modelo liberal afirmando que este pretende "descrever a produção em contraste com a distribuição [...] como sujeita a leis eternas, independentes da História, e substituí-las de modo capcioso pelas relações burguesas, que seriam leis imutáveis da sociedade in abstrato" (M ARX, 1972, p. 25). Mas a moderna teoria econômica afirma que são essas leis que mantém o equilíbrio econômico, e a corrente marxista considera-a uma teoria externa à realidade, nas palavras de Oscar Lange (1972, p. 67), "a esterilidade da teoria do equilíbrio econômico geral se deve à sua complexidade e alto grau de abstração, que Ihe impossibilitam a aplicação a problemas reais".

A teoria econômica considera um "equilíbrio estático" que avalia o desenvolvimento econômico a partir de "um sistema de dados e mecanismos constantes mediante os quais os preços e as quantidades produzidas se ajustam às mudanças nele ocorridas" (LANGE, 1972, p. 70). Dessa forma, os dados da realidade não importam ao modelo liberal, "à medida que ela é meramente uma teoria de distribuição dos recursos escassos entre diferentes usos" (LANGE, 1972, p. 70).

Para desenvolver sua teoria, Marx se utiliza de um método denominado materialismo histórico, que observa criticamente o desenvolvimento da sociedade. De acordo com as leis imutáveis dos economistas burgueses, Marx afirma que as relações, determinadas a partir do desenvolvimento da economia, se desdobram de maneira cíclica, referindo-se à dialética. Dessa forma, Marx se refere ao desenvolvimento da sociedade de maneira profética, prevendo o esgotamento e conseqüente superação do modelo capitalista que transita para a ditadura do proletariado. "Juntamente com a teoria do materialismo 
histórico, a teoria da evolução explica as mudanças reais que ocorrem no sistema capitalista e lhe confere bases para prever o futuro" (LANGE, 1972, p. 83).

De maneira geral, e superficial, sua teoria consiste em descrever os processos de transformação social os quais são decorrentes da luta de classes. As classes são categorias que habitam no Estado, ou seja, na existência do Estado, podem ser observadas diferentes classes. 0 autor afirma que, para conhecer o contexto político econômico de determinado lugar, é preciso analisar a população sob a noção de que esta é constituída por classes bem como as relações que delas nascem (M ARX, 1972, p. 38).

\section{Limites do modelo republicano}

Vontade geral e autonomia: Jean Jacques Rousseau

Se por um lado, o liberalismo busca entender a sociedade a partir do indivíduo, as doutrinas Que explicam o comunitarismo desenvolvem sua teoria pensando a sociedade como um todo. Dessa forma, confrontam-se elementos como a propriedade privada e a propriedade comunitária, bem como a questão do papel do Estado na sociedade. 0 comunitarismo visualiza os indivíduos como cidadãos, os quais desempenham um papel fundamental na sociedade. Assim, entende-se que a sociedade deve se desenvolver em direção ao autogoverno político, o que demanda uma série de condições, inclusive econômica.

Segundo Gargarella, para que os cidadãos efetivamente participem das decisões do Estado, é preciso que discutam acerca de todas as suas questões políticas e, dessa forma, ele expõe a conexão entre política e economia através, entre outros, do argumento de que são as desigualdades econômicas que geram as desigualdades sócio-políticas. Os indivíduos mais desenvolvidos economicamente são a parte mais apta da sociedade a discutir racionalmente os fatos políticos da sua comunidade, seja pelo maior acesso às instituições, pela educação, alimentação, entre outros, o que deixa em uma posição diferenciada, e marginalizada politicamente, indivíduos de baixa renda (GARGARELLA, 2006).

Como representante deste pensamento figura Jean Jacques Rousseau, que delimita o momento da socialização ao momento do chamado contrato social, em que os indivíduos decidem abrir mão de sua liberdade irrestrita do estado de natureza para formar uma ordem 
social. Neste momento Rousseau afirma que, na verdade, substitui-se uma liberdade natural por uma liberdade civil, de onde decorrem ganhos e perdas. A liberdade natural encontra seu limite na força do indivíduo, enquanto a liberdade civil é limitada pela vontade geral (ROUSSEAU, 1999).

O pensador entende a sociedade de acordo com uma visão orgânica, em que 0 Estado é considerado um corpo moral, o qual tem sua existência dependente dos membros que o constituem. Dessa forma, o pacto social gera um poder, o qual é guiado pela vontade geral, sobre todos os seus membros, o que Rousseau denomina soberania.

Não sendo o Estado ou a Cidade mais do que uma pessoa moral, cuja vida consiste na união de seus membros, e se o mais importante de seus cuidados é o de sua própria conservação, torna-se-Ihe necessária uma força universal e compulsiva para mover e dispor cada parte da maneira mais conveniente a todos. Assim como a natureza dá a cada homem poder absoluto sobre todos os seus membros, o pacto social dá ao corpo político um poder absoluto sobre todos os seus, e é esse mesmo poder que, dirigido pela vontade geral, ganha, como já disse, o nome de soberania (ROUSSEAU, 1999, p. 95).

Importa, neste momento, analisar o conceito de vontade geral, uma vez que dele decorre a compreensão da autonomia do indivíduo perante o corpo social, o que se coloca num âmbito diametralmente oposto às teorias liberais. Se estas priorizam os interesses individuais, Rousseau as confronta a partir de suas bases republicanas.

Em primeiro lugar, é preciso frisar uma distinção que o próprio autor faz questão de expor: a diferença entre a vontade de todos e a vontade geral. Esta, se refere aos interesses universalizáveis, enquanto aquela trata meramente da soma dos interesses individuais.

Há comumente muita diferença entre a vontade de todos e a vontade geral. Esta se prende somente ao interesse comum; e a outra, ao interesse privado, e não passa de uma soma das vontades particulares. Quando se retiram, porém, dessas mesmas vontades, os a-mais e os a-menos que nela se destroem mutuamente, resta, como soma das diferenças, a vontade geral (ROUSSEAU, 1999, p. 91-92).

Sendo a soberania considerada indivisível (ROUSSEAU, 1999, p. 87), a vontade geral é um elemento uno, em que qualquer decisão que se refira à coletividade deve atentar às expectativas de todos, ou seja, ao interesse comum. Como acentua o autor: "[...] a vontade ou é geral, ou não o é; ou é a do corpo do povo, ou somente de uma parte" (ROUSSEAU, 
1999, p. 87). Assim, de acordo com tal visão, não há espaço para o interesse individual, uma vez que a liberdade do cidadão encontra-se implícita na sua relação com o Estado.

A esta noção relaciona-se a idéia de autonomia em Rousseau, pois, para ele, cada cidadão deve agir como um membro do Estado, uma vez que não se separa dele. Ele menciona a necessidade de distinção entre os direitos do soberano e dos cidadãos, no entanto, quando se refere à noção de iguais direitos, coloca a esfera individual condicionada à esfera pública e, inclusive, fundamenta as ações privadas de acordo com o corpo social.

Os compromissos que nos ligam ao corpo social só são obrigatórios por serem mútuos, e tal é sua natureza, que ao cumpri-los, não se pode trabalhar para si mesmo. Por que é sempre certa a vontade geral e por que desejam todos constantemente a felicidade de cada um, senão por não haver ninguém que não se aproprie da expressão cada um e não pense em si mesmo ao votar por todos? - eis a prova de que a igualdade de direito e a noção de justiça, por aquela determinada, derivam da preferência que cada um tem por si mesmo, e, conseqüentemente da natureza do homem; a prova de que a vontade geral, para ser verdadeiramente geral, deve sê-lo tanto no objeto quanto na essência; a prova de que essa vontade deve partir de todos para aplicar-se a todos, e de que perde sua explicação natural quando tende a algum objetivo individual e determinado, porque então, julgando aquilo que nos é estranho, não temos nenhum princípio verdadeiro de equidade para guiar-nos (ROUSSEAU, 1999, p. 96).

Não há, portanto, uma distinção entre a autonomia privada e a autonomia pública, uma vez que a noção republicana de sociedade considera apenas a posição do cidadão perante a ordem social. Isso faz com que o pensador da teoria social, Jurgen Habermas, dirija suas críticas à sobrecarga ética do modelo defendido por Rousseau, tema a ser abordado adiante.

Com a palavra, Jurgen Habermas

Jurgen Habermas atribui a sobrecarga ética da teoria de Rousseau, em relação à autonomia, pela sua aproximação com a tradição republicana. Para Rousseau, a partir da noção de que os indivíduos, antes isolados, unem-se em uma ordem social através de um pacto, o qual busca a conservação dos membros, constitui-se a soberania do povo. Ou seja, o contrato gera uma socialização em que os participantes de uma comunidade encontram-se unidos em um corpo social indivisível. A soberania, dessa forma, se constitui como um poder o qual é guiado pela vontade geral, que se caracteriza pelo interesse comum. Habermas destaca o conceito de vontade geral, como vontade unificada dos cidadãos, em que trata dos interesses comuns. 
Através do medium de leis gerais e abstratas, a vontade unificada dos cidadãos está ligada a um processo de legislação democrática que exclui per se todos os interesses não-universalizáveis, permitindo apenas regulamentações que garantem a todos as mesmas liberdades subjetivas (HABERM AS, 2003, p. 136).

A crítica em relação à sobrecarga ética que Habermas dirige a Rousseau, e que se refere à influência republicana, se fundamenta na atenção maior que o autor oferece ao aspecto ético do que ao aspecto moral, o que acaba desencadeando num conceito de autonomia que se constitui “[...] como a realização consciente da forma de vida de um povo concreto" (HABERM AS, 2003, p. 136).

Enquanto membros de um corpo coletivo, eles se diluem no grande sujeito de uma prática de legislação, o qual rompeu com os interesses singulares das pessoas privadas, submetidas às leis. Rousseau exagerou ao máximo a sobrecarga ética do cidadão embutida no conceito republicano de sociedade. Ele contou com virtudes políticas ancoradas no ethos de uma comunidade mais ou menos homogênea, integrada através de tradições culturais comuns.

No entanto, para que se mantenha tal unidade, Rousseau afirma que é preciso um Estado forte, principalmente quando abriga um grande número de membros. Nessas condições, então, a coerção se constitui como único meio para que a vontade geral prevaleça diante dos interesses particulares.

Porém Rousseau não consegue entender a prática da autolegislação, quando esta precisa alimentar-se da substância ética de um povo que já se entendeu preliminarmente sobre suas orientações axiológicas, ou seja, ele não pode explicar a possibilidade de uma mediação entre a requerida orientação pelo bem comum dos cidadãos e os interesses sociais diferenciados das pessoas privadas, ou melhor, não sabe dizer como é possível mediar, sem repressão, entre a vontade comum, construída normativamente, e 0 arbítrio dos sujeitos singulares (HABERMAS, 2003, p. 137).

Além disso, Habermas (2003, p. 137) afirma que Rousseau se apega às "propriedades lógico-semânticas" das leis gerias e abstratas a fim de esclarecer o sentido da igualdade do conteúdo do direito e questiona a eficácia, em relação à validade das normas gerais, da forma gramatical.

A pretensão segundo a qual uma norma é do interesse simétrico de todos tem o sentido de uma aceitabilidade racional - todos os possíveis envolvidos deveriam poder dar a ela o seu assentimento, apoiados em boas razões. E isso só pode evidenciar-se sob as condições pragmáticas de discursos nos quais prevalece 
apenas a coerção do melhor argumento, apoiado nas respectivas informações (HABERM AS, 2003, p. 137).

Habermas (2003, p. 137) busca resolver tal situação de acordo através das "[...] condições pragmáticas que determinam como se forma a vontade política [...]", ou seja, o exercício da autonomia política, para ele, só pode ser garantido através de um processo de "[...] formação discursiva da opinião e da vontade, não através das leis gerais".

Ao atribuir a Rousseau a crítica acerca da sobrecarga ética de seu modelo, Habermas demonstra sua preocupação em conciliar a vida privada dos indivíduos com sua vida política. Para ele, é preciso criar condições para que os integrantes de uma comunidade possa desenvolver sua autonomia em ambas as direções, o que o leva a relacionar os direitos humanos, de caráter subjetivo, e a soberania do povo.

\section{Conclusão}

Ao confrontar duas teorias aparentemente inconciliáveis, é possível perceber alguns limites que ambas possuem, seja no que se refere à compreensão da sociedade, bem como em relação à função do Estado. A fim de compreender os processos sociais, cada uma parte de um referencial distinto. No caso do liberalismo, compreende-se a sociedade a partir do indivíduo, uma vez que a sociedade é interpretada como a soma das expectativas deles. De outra forma, a noção republicana considera o cidadão imerso em uma ordem política, em que sua individualidade está implícita em sua relação com a sociedade.

Neste momento, a teoria habermasiana busca solucionar tal conflito deixando de lado a idéia de polarização e empenhando-se na conciliação entre ambos. Habermas busca destacar as potencialidades de cada teoria sem, contudo, afirmar uma ou outra absolutamente. Ele destaca que existe uma "[...]relação não esclarecida entre direito subjetivo e público no âmbito da dogmática jurídica [...]", do que decorre uma certa impotência para "[...] harmonizar conceitualmente e de modo satisfatório autonomia pública e privada [...]" (HABERM AS, 2003, p. 115). Ele afirma que "[...] os direitos políticos também devem poder ser interpretados como liberdades de ação subjetivas [...]" (HABERMAS, 2003, p. 116), uma vez que a autonomia privada e pública pressupõem-se de forma mútua. 
Assim, de acordo com sua liberdade comunicativa, o indivíduo pode assumir papéis distintos. "Por isso, a autonomia privada de um sujeito do direito pode ser entendida essencialmente como a liberdade negativa de retirar-se do espaço público das obrigações ilocucionárias recíprocas para uma posição de observação e influenciação recíprocas" (HABERMAS, 2003, p. 156). Por outro lado, "a idéia da autolegislação de civis exige que os que estão submetidos ao direito, na qualidade de destinatários, possam entender-se também enquanto autores do direito" (HABERM AS, 2003, p. 157).

Diante da necessidade de se posicionar perante uma ou outra teoria, por muitas vezes deixamos de lado a observância às potencialidades de cada uma dela e em que medida elas se atentam à realidade social e, inclusive, aos objetivos da sociedade contemporânea. Pensando nisso, fora percebida a necessidade de relacionar dois modelos aparententemente contrários, mas que, em sua essência, contribuem para pensar a sociedade em que vivemos.

Tratamos, no presente trabalho, que compartilhamos de uma realidade liberal, que atinge as instituições, inclusive 0 direito. No entanto, a teoria liberal apresenta limites que não dão conta, por exemplo, de explicar a desigualdade e a mobilidade social, uma vez que estes fatores se relacionam com uma condição histórica.

Por outro lado, existe um modelo que concentra seu potencial nas questões sociais e, por esse motivo, muitas vezes, é criticado pela sua sobrecarga ética, o republicanismo. Jurgen Habermas se apresenta no meio dessas duas posições, ao perceber a realidade social e suas necessidades. Ele busca, então relacionar ambos os modelos a fim de obter um equilíbrio entre as esferas pública e privada.

\section{Referências}

BOBBIO, Norberto. A Era dos Direitos. Rio de Janeiro: Elsevier, 1992. . Liberalismo e Democracia. Rio de Janeiro: Editora Brasiliense, 2000.

GARGARELLA, ROBERTO. As precondições econômicas do autogoverno político. In: FILOSOFIA Política Contemporânea: controvérsias sobre civilização. 1. ed. Buenos Aires: Consejo Latinoamericano de Ciências So ciales - CLACSO; São Paulo: Departamento de Ciência Política. Faculdade de Filosofia, Letras e Ciências Humanas. Universidade de São Paulo, 2006.

GORENDER, Jacob. Marxismo sem Utopia. São Paulo: Ática, 2000. 
HABERM AS, Jürgen. Direito e Democracia: entre facticidade e validade. Rio de Janeiro: Tempo Brasileiro, 2003. v. 1.

HOROWITZ, David. A Economia M oderna e o M arxismo. Rio de Janeiro: Zahar editores, 1972.

LANGE, Oscar. A Economia M arxista e a M oderna Teoria Econômica. In: HOROWITZ, David. A Economia Moderna e o M arxismo. Rio de Janeiro: Zahar editores, 1972.

LOCKE, John. Segundo Tratado sobre o Governo Civil: ensaio sobre a origem, os limites e os fins verdadeiros do governo civil. Petrópolis: Editora Vozes, 2001.

M ARX, Karl. Introdução à Crítica da Economia Política. In: HOROWITZ, David. A Economia Moderna e o Marxismo. Rio de Janeiro: Zahar editores, 1972. p. 25-38.

ROUSSEAU, Jean Jacques. O Contrato Social. São Paulo: Abril Cultural, 1999. . Discurso sobre a Origem e os Fundamentos da Desigualdade entre os Homens.: São Paulo: Abril Cultural, 1999. 